\title{
A lower minimum legal drinking age was associated with increased suicide in youths 18-23 years of age
}

Birckmayer J, Hemenway D. Minimum-age drinking laws and youth suicide, 1970-1990. Am J Public Health 1999

Sep;89:1365-8.

QUESTION: Does an association exist between the minimum legal drinking age (MLDA) and suicide among young people?

\section{Design}

Population-based time series for 1970-90.

\section{Setting}

48 contiguous states in the US.

\section{Participants}

Population figures were derived from the US censuses for 1970, 1980, and 1990. Data for the intervening years were calculated by attributing one tenth of the population change to each year.

\section{Assessment of risk factors}

The MLDA for beer was obtained from state statutes. The following potential confounding variables were also assessed: rates of high school completion, divorce, and unemployment; level of enforcement of drinking laws (police per capita and number of drinking law arrests); proportion of state residents living within 30 miles of a bordering state with a lower MLDA; and state tax on beer.

\section{Main outcome measure}

Suicide data were obtained from the Mortality Files of the National Center for Health Statistics.

\section{Main results}

A fixed effects Poisson maximum likelihood regression model was used to estimate the association between MLDAs and suicide. After controlling for potential confounding variables, higher suicide rates were seen among young people (18-23 y of age) who lived in states with an MLDA of 18 years compared with 21 years $(\mathrm{p}<0.01$ for $18-20 \mathrm{y}$ of age and $\mathrm{p}<0.05$ for $21-23$ $y$ of age) (table). No association between the MLDA and suicide was seen in young people who were $15-17$ years of age.

\section{Conclusion}

In young people who are 18-23 years of age, a lower minimum legal drinking age was associated with an increased suicide rate.

Associations between a lower minimum legal drinking age (MLDA) and suicide

\begin{tabular}{lll} 
Age & $\begin{array}{l}\text { Increase in suicide for MLDA } \\
\text { of } 18 \mathrm{y} \mathbf{2 1} \mathbf{y}^{*}\end{array}$ & p value \\
\hline $18-20 \mathrm{y}$ & $8 \%$ & $<0.01$ \\
\hline $21-23 \mathrm{y}$ & $6 \%$ & $<0.05$ \\
\hline
\end{tabular}

*Adjusted for proportion of residents within 30 miles of a bordering state with lower MLDA, education, divorce, unemployment, drinking law arrests, police per capita, and beer tax.

\section{COMMENTARY}

Birckmayer and Hemenway have completed a carefully conceived study showing an association between a lower MLDA and an increased suicide rate. Other research has shown that higher MLDAs are associated with lower levels of alcohol use among high school seniors and recent high school graduates ${ }^{1}$ and with reductions in deaths for motor vehicle drivers, unintentional injuries, and suicide. ${ }^{1-2}$ The authors noted that although these findings are not new, the potential effects on youth suicide compared with death from other causes did not contribute substantially to policy decisions about raising the MLDA.

A recent natural experiment highlights the relation between alcohol intake and suicide and the impact of government policies restricting alcohol on suicide as well as on other causes of violent death. Wasserman et al presented data on the decline in suicide rates of 32\% for men and 19\% for women during perestroika, 1984-90, in the former Soviet Union. ${ }^{3-4}$ The reduction in suicides has been hypothesised to result from Gorbachev's restrictive anti-alcohol campaign that substantially raised the prices of alcoholic beverages rather than from other sociopolitical changes.

These 2 examples by Birckmayer and Hemenway and Wasserman et al underscore how mental health professionals must translate data about access to alcohol or guns into public policy initiatives that may be central to the prevention of suicide among young people.

Paul Links, MD St Michael's Hospital Toronto, Ontario, Canada

1 O'Malley PM, Wagenaar AC. Effects of minimum drinking age laws on alcohol use, related behaviors and traffic crash involvement among American youth: 1976-1987. I Stud Alcohol 1991;52:478-91.

2 Jones NE, Pieper CF, Robertson LS. The effect of legal drinking age on fatal injuries of adolescents and young adults. $A m$ J Public Health 1992;82:112-5.

3 Wasserman D, Varnik A, Eklund G. Male suicides and alcohol consumption in the former USSR. Acta Psychiatr Scand 1994;89:306-13.

4 Wasserman D, Varnik A, Eklund G. Female suicides and alcohol consumption during perestroika in the former USSR. Acta Psychiatr Scand Suppl 1998;394:26-33.
Source of funding National Institute on Alcohol Abuse and Alcoholism.

For correspondence: $D$ D Hemenway, Department of Health Policy and Management, Harvard School of Public Health, 677 Huntington, Avenue Boston, MA 02115, USA.Fax +1617432 4494. 